\title{
Performance Measurement and Improvement of Healthcare Service Using Discrete Event Simulation in Bahir Dar Clinic
}

Aregawi Yemane ${ }^{1}$, lecturer in Ethiopian institute of technology- Mekelle, industrial engineering, Mekelle university, Ethiopia, aregawi.meresa@mu.edu.et

Hagazi Abrha ${ }^{2}$, lecturer in Ethiopian institute of technology- Mekelle, industrial engineering, Mekelle university, Ethiopia, hagaziabrha88@gmail.com

Kidane Gidey ${ }^{2}$, lecturer in Ethiopian institute of technology- Mekelle, industrial engineering, Mekelle university, Ethiopia, kidane29@gmail.com

\begin{abstract}
This paper deals with the service performance analysis and improvement using discrete event simulation has been used. The simulation of the heath care has been done by arena master development 14 -version software. The performance measurement for this study are patients output, service rate, service efficiency and it is directly related to waiting time of patients in each service station, work in progress, resource utilization.

Simulation model was building for Bahir Dar clinic and then, prepared the proposed model for the system. Based on the simulation model run result, the output of the existing healthcare service system is low due to presence of bottlenecks on the service system. Moreover, the station with the largest queue and high resource utilization are identified as a bottleneck. The bottlenecks, which have identified are reduced by using reassigning the existing resources and add new resources and merging the similar services, which has under low resource utilization (nurses). Finally, the researchers have proposed a developed model from different scenarios. Moreover, the best scenario is developed by combining scenario 2 and 3 . And then, service efficiency of the healthcare has increased by 9.86 percent, the work in progress (WIP) are reduced by 3 patients from the system and the service capacity of the system is increased 34 to 40 patients per day due to the reduction of bottleneck stations.
\end{abstract}

Keywords: - Discrete Event Simulation, Performance Analysis, WIP, Model, Healthcare

\section{Introduction}

Healthcare industry is among the largest industries in Ethiopia.Its service provision is one of the priority service area for the population. In order to acheive this health is becoming a growing concern from time to time in Ethiopia and healthcare centers have been 
built. According WHO report in 2010 and ministry of Ethiopian health office in 2010 showed that there is $17.7 \%$ to $46 \%$ growth in the overall health care centers (Eshetie, Selam, \& Sisay, 2018). And (Sally \& Shivam, 2010) showed that, the quality and responsibility of medical care service in Ethiopia is still among the least ones as compared to the sub Saharan African countries. Heathcare service are confront challengs are physician shift from one place to another, lack of take responsiveness etc.In addition to this, (Eshetie, Selam, \& Sisay, 2018) found that designing an optimum balance between customers' demand and available resources in the clinic is one of the main problem has subsequently resulted in long patient waiting time in the healthcare centers. and hospitals in Ethiopia. The amount of time that patients wait to receive service in healthcare centers is one factor, which affects the performances of the health care services. Patient satisfaction is one important quality parameter in healthcare centers. (Kelton, 2002) showed that discrete event simulation has the capability to characterize complex systems and in healthcare can facilitate the decision-making process for operational and management decisions.

(Eshetie, Selam, \& Sisay, 2018) showed that Simulation studies can optimize patient scheduling, resource utilization, healthcare decision making, patient flow and patient throughput.

Discrete event simulation is widely used in the simulation of healthcare systems, agent technology is a good choice for use in healthcare applications as it best characterizes the operation of complex systems such as emergency department (Eduardo, Manel, MaLuisa, Francisco, \& Emilio, 2012).

The advantages of the simulation approach derive from its flexibility, as well as from its ability to manage the variability, uncertainty and complexity of dynamic systems. Simulation is particularly useful when a problem has significant uncertainties, which require stochastic analyzes (MIELCZAREK, 2016).

A clear understanding of this often overlooked concept is crucial for the healthcare model community, which is seeking better stakeholder engagement, demonstration of value and quality assessment (Junqiao, David, Mónica, \& Alexandra, 2019).
Bahir Dar health center ( Bahir Dar clinic ) is one of the $10^{\text {th }}$ heath care facility service found in the city which is established in 1951 E.C. It is located in the capital city of amhara region bahir dar city whichis 565 $\mathrm{km}$ northern of addis abeba. The facility plans about 60,572 population to serve in ayear.

\subsection{Statement of the problem}

Now adays, Ethiopian healthy sector service delivery system improvment has been practiced by many health center. Howerever, they do not faced their serous challenge that happed in the patients. Long waiting time has found to be a major source of patient dissatisfaction and it increases the proportion of patients who leave without seen by a doctors.

Averagely in Bahir Dar clinic 70 patients are arrived in a day. But they have served 35 patients in a day. So they served only $50 \%$ of the total arrived patients. The reason behind the problems are servicing and their resource allocation are not well organized. As a result, the longest patients waiting time is 180 minutes in a system to get a service. Due to this reason, patients had exposed to extra cost, stress and fatigue.

\subsection{Objective of the study}

\subsubsection{General objective}

The main objective of this paper is to measure and improve the performance analysis of the clinic using discrete event simulation.

\subsubsection{Specific objective}

In order to accomplish the general objective of the study they should have do the following specific objectives. These are:

$>$ To model the existing system of the clinic

$>$ To study the root cause of waiting time of patients

$>$ To identify the bottleneck station of the clinic 
To propose and develop an improved model of the clinic

\section{Literature review}

According to (Haussmann, 1970) waiting time is an important determinate factor of quality services as it is noted that in health care provision delays are expensive and in terms of the potential costs of decreasing patient satisfaction and adverse outcome.

(Kelton, 2002) shows simulation refers to the broad collection of application and methods to mimic the characteristics of real systems, usually on a computer with Rockwell arena software. Since many simulation models involve waiting lines or queues as a building block, we would start a very simple case such a model representing a portion of a servicing facility. Patient arrives to a servicing center; they processed by a single channel, and then leave.

Healthcare organizations have come under increasing pressure to provide quality care by addressing rising costs, lower reimbursements and new regulatory demands. Discrete event simulation has become a popular and effective decision-making tool for optimal allocation of scarce healthcare resources to improve patient flow, minimizing healthcare costs and increasing patient satisfaction (Sheldon, Shane, \& James, 2006).

This is the logical structure of a model: In this document, you can get high-quality solutions in seconds compared to manually prepared schedules that take a lot of time and effort (Topaloglu, 2009).

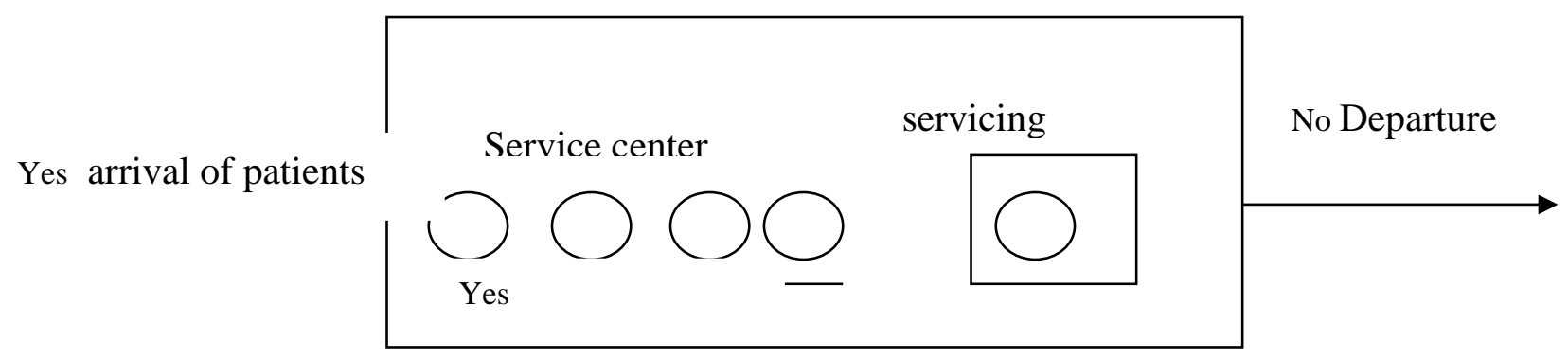

Fig. 1. a simple processing system

\subsection{Pieces of simulation}

Entities: in a system, an object of interest called an entity. In our case company Bahir Dar clinic, entities are number of patients that require service.

Queues: Is the number of patients waiting in the line to get service from the clinic.

Attributes: are common characteristics of patients in the system. The characteristics could have color, priority, property, age and sex.
Resources: are facilities/machines or persons in the system that provides services to the system entities. In our case company Bahir Dar clinic resource are nurses, lab technicians, card class workers and casher.

Variables: they used to store information or values that describe or reflect some characteristics of the system. In our case, Bahir Dar clinic variables had shown the busyness or idleness of the operations in the clinic. There are two types of variables: arena built in variables, which mean number in queue, number of busy resources, simulation time, etc., and user defined 
variables, which mean number in system, current shift, etc.

The simulation event list: is a means of keeping track of the different things that occur during a simulation run and an instantaneous change in time of the system.

Statistical accumulators: used for performance measurement as result used to measure waiting time of patients, number of patients passed in the queue, utilization of resources and bottleneck operations in the clinic. All of these accumulators should initialize to zero.

Events: an event is something that happens at an instant of time that might change attributes, variables and statistical accumulators. In addition, there are three kinds of events: arrival that is a new patient enters to the system, departure that is a patient leaves from the system after getting a service and the end the simulation stopped at a time.

Starting and stoping time: Important, but sometimes overlooked, issues in a simulation are how it will start and stop. Arena does many things for you automatically, but it cannot decide modeling issues like starting and stopping rules. You have to determine the appropriate starting conditions, how long a run should last, and whether it should stop at a particular time or whether it should stop when something specific happens. It's important to think about this and make assumptions consistent with what you are modeling; this decision can have just as great an effect on your results as can more obvious things like values of input parameters (such as inter arrival time means, service time variance and the number of machines)

In discrete event simulation model, the variables that describe the system do not change between successive events of the patients (Kelton, 2002).
Independent arrivals and scheduled appointments, as well as new declarations and features, have been carefully designed to solve unique simulation problems specific to hospitals and healthcare (Heflin \& Harrell, 1998).

(Appah, Sam, \& Alex, 2014) and (Umar, Oche, \& Umar, 2011) States that, the waiting time of patients for getting a service is lengthy in most of the developing counties.

(Globerman, 2013) define the waiting time of a patient is the length of time when the patient enters the outpatient clinic and Most waiting time is due to unbalanced workload distribution among medical workers or few numbers of nurses in some service areas. By considering the various conditions of patients in the system, the waiting time of patients in the health care center categorized as follows:

1. Retrospectively: the actual measured waiting time for those who received care.

2. Prospectively: which have the expected waiting time for those who need care

3. Cross-sectional: the elapsed waiting time of those currently waits for care as of a specific date.

\subsection{Theoretical background of waiting time in health care}

(Vos, Groothus, \& Van, 2007) showed that health care organization has been a view with the context of queuing system in which patients arrive, wait for service, obtain service, and then depart from the health center.

The systems engineering design and development processes are examined with particular attention to the discovery of requirements, models and simulation scenarios. 


\section{Factors associated with waiting time a health facility}

Patient flow: Patient flow shows the ability of the healthcare system to serve patients quickly and efficiently as they move through stages of care. Blockage in the flow can increase waiting and throughput time creating a negative effect on the quality of service delivery (Vos, Groothus, \& Van, 2007).

High Workload: The physicians are overworked, and then patients have to wait longer as staffs have too many patients to attend. This can be solved by shifting staff from facilities with a low workload.

Lack of efficiency: Patients may not effectively attend to because much as physicians are present at the service point they are busy with something else; such as teaching, administrative work or preparation.

A logistical problem: Patients may be waiting to see and physician is available to see patients but due to a lack of equipment, rooms or other logistical needs, physician is unable to attend the patients. There was physician present but patients waiting.

Queuing problems: This occurs when patients attended to clinic in an illogical order, that is the patients are not attending in the order that they arrive at the service point.

\section{Methodology}

The data and the current information are need for a better and prefect well, since the project is dependent on the current actual data of the case company. The researcher has used some techniques for gathering and acquiring information from our case campany, which is bahir dar clinic.

\subsection{Sample size determination}

Sample size criteria to determine the appropriate sample size: Purpose of the study, the population size, the level of precision, the level of confidence or risk and the degree of variability in the attribute being measured.

The level of precision: Sometimes-called sampling error is the range in which the true value of the population has been estimating. This range is often expressing as in percentage point $\pm 5 \%$ (Israel, 1992).

The level of confidence or risk: the level of confidence or risk level is based on ideas encompassed under the Central Limit Theorem. The key idea encompassed in the Central Limit Theorem is that when the population is repeatedly sampled, so the average value of the attribute obtained by those samples is equal to the true population value. Furthermore, the value obtained by these samples is distributed normally about the true value. In a normal distribution, approximately $95 \%$ of the sample values are within the two standard deviations of the true population value (Israel, 1992).

The degree of variability: the degree of variability in the attributes being measured refers to the distribution of attributes in the population. The more heterogeneous a population, the larger sample size required to obtain a given level of precision. The less variable (more homogeneous) a population, the smaller the sample size required. Note that a proportion of $50 \%$ used indicates a greater level of variability than either $20 \%$ or $80 \%$ used. Because a proportion of $50 \%$ indicates the maximum variability in a population, it is often used in determining a more conservative sample size. Since this was a cross sectional survey, the sample size was calculated using the Kish Leslie formula for determining sample size. 
From the previous report of the clinic found that 50\% of patients said they had servedin a day. Therefore, we shall use this proportion as $\mathrm{p}=50 \%$, which means $50 \%$ of the patients depart from the system after getting service, but $50 \%$ of the patients were not get a service from the system in a day.

For this study $95 \%$ confidence level was used, making $\mathrm{Z}=1.96$, while the power for the study was $95 \%$, so $Z_{\beta}=0.05$ this power of $95 \%$ was important. Since, it helped the researcher to correctly notice a difference that actually existed.

$N=\frac{Z^{2} P(1-P)}{d^{2}}$

where; $\mathrm{N}=$ sample size estimate of patients attending in the clinic.

\subsection{Data Collection and Analysis}

\subsubsection{Data collection}

For fivedays' data was collected about patients' arrival time, transfer time and service time of over 384 patients using stopwatch in Bahir Dar clinic for each service stations. The researchers have collected the appropriate data by applying both primary and secondary data collection techniques. And then, the researchers have seen the following points during observation time: - Arrival time of patients, Number of queues, Allocation of workers and How the processes are organized? Apparently, from the observation it is clear that there is no performance analysis study has done before this time from any researcher in the case study place Bahir Dar clinic. The clinic has no formal performance measurement system but they have mid yearly report that used checking the performance of the service stations as the whole by comparing with key performance indicators(KPI) as
$\mathrm{P}=$ proportion of patients that are served $=50 \%$

$1-\mathrm{p}=$ proportion of patients that are not served $=1-$ $\mathrm{p}=50 \%$

$\mathrm{Z}=$ standard normal deviate at $95 \%$ confidence interval corresponding to 1.96

$\mathrm{d}=$ absolute error between the estimated and true mean waiting time which is 0.05

$\mathrm{N}=1.96 * 1.96(0.5 * 0.5) / .05 * .05$

$\mathrm{N}=384.16 \cong 384$ patients

Therefore, we have taken 384 patients to analysis the performance of the system.

the reference or standard. There are five main service stations in Bahir Dar clinic. The service stations are card room, casher room, pharmacy room, OPD room and laboratory room. Specially card room, laboratory room and OPD room have long queues during morning session and relatively decrease afternoon session. However, the laboratory room has the longest queues most of the clinic working hours. The reason that created long queues in the service station are: Slow service system, the servers are not committed, less employee skill and Not have enough server. 384 patients' data was collected in five day's for eight hours working time in the system of the clinic. The following table has arrival of patients; inter-arrival time of patients, service time of each station and transfer time of one station to other stations in the system of the clinic. Assume that the variation between arrival of patients has been less than one minute, then consider arrival of patients in the system at the same time. 


\subsubsection{Data analysis}

After collection of enough data with sufficient number of observation, recording data and interview, then we analyze it. For this analysis, Rockwell arena software were used as a tool to model and know the length of waiting time of the patients, the bottleneck of the station and number of resource utilized. The model must be constructed looking to be as close as possible to the real system under study, for that, some steps would be taken to obtain better results consistent with the expected goals. For proper performance of discrete event simulation, some steps should be following to achieve success with the study. Follows the ten steps that we believed are necessary.

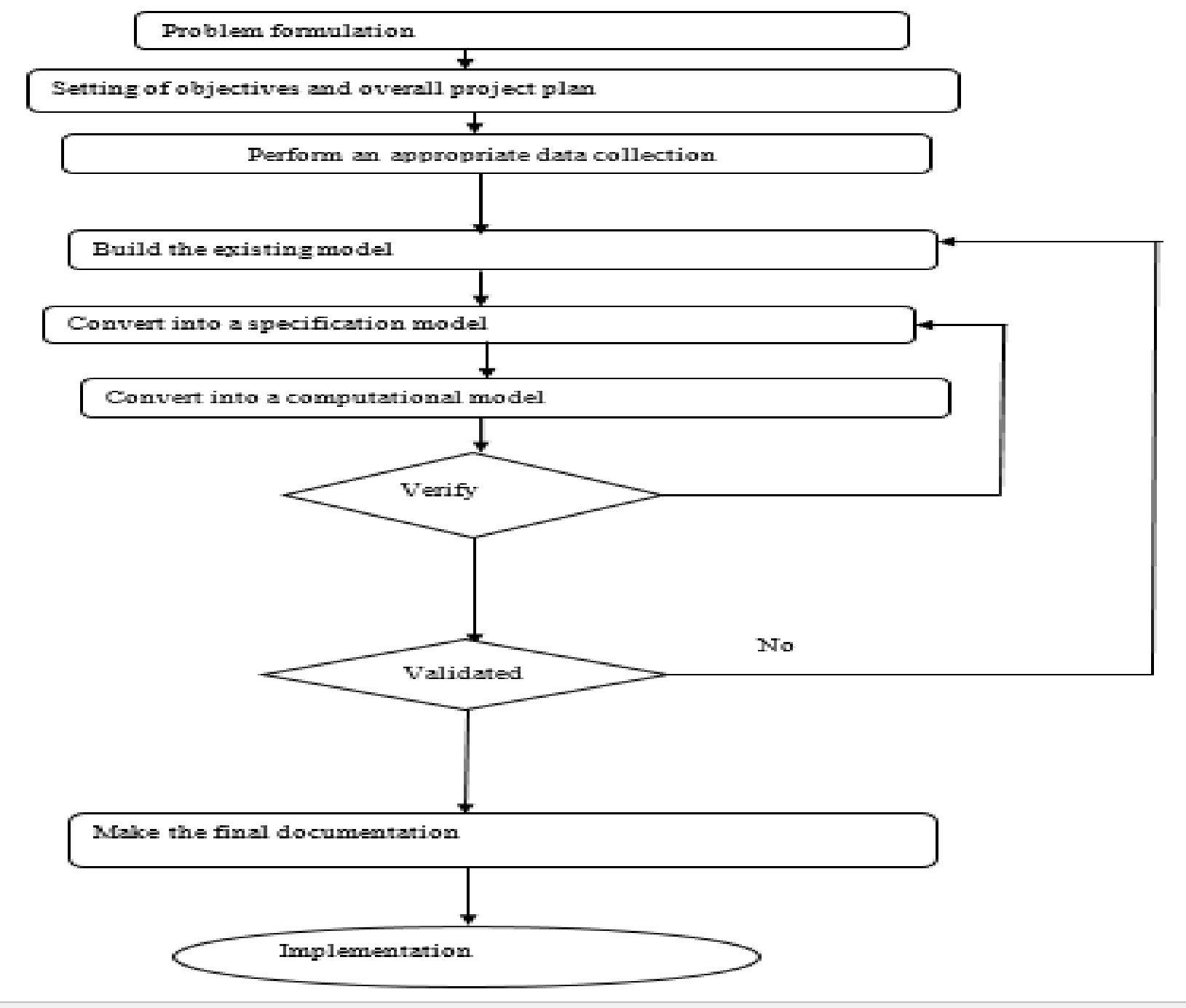

Fig. 2. simulation steps

Input Analysis: Distribution of inter arrival time of patients 


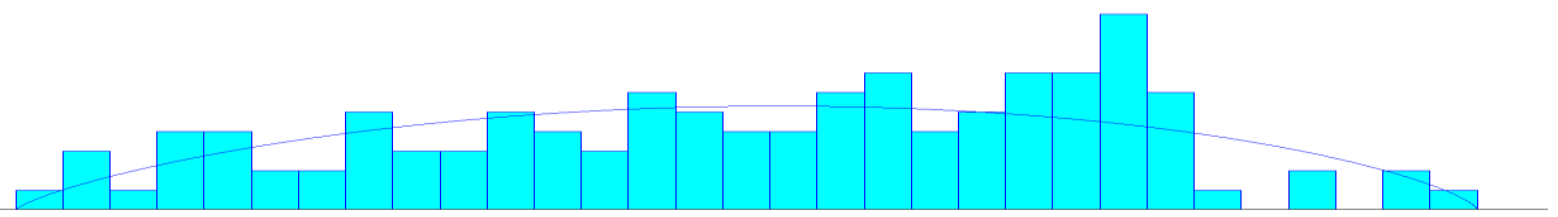

Fig. 3. input analyzer data distribution of inter arrival of patients

Distribution: Beta

Expression: $\quad 7.5+31 * \operatorname{BETA}(1.77,1.71)$

Square Error: $\quad 0.007475$

Chi Square Test

Number of intervals $\quad=10$

Degrees of freedom $\quad=7$

Test Statistic $\quad=11.9$

Corresponding $\mathrm{p}$-value $=0.104$

Data Summary

$\begin{array}{ll}\text { Number of Data Points } & =117 \\ \text { Min Data Value } & =8 \\ \text { Max Data Value } & =38 \\ \text { Sample Mean } & =23.3 \\ \text { Sample Std Dev } & =7.32\end{array}$

Histogram Summary

Histogram Range $\quad=7.5$ to 38.5

Number of Intervals $=31$

Table 1. resource and operation time distribution

\begin{tabular}{|c|c|c|c|}
\hline Data type & Distribution & expression & Resources \\
\hline Arrival of patients & Lognormal & $0.5+\operatorname{LOGN}(3.16,3.44)$ & \\
\hline Inter arrival time & Beta & $7.5+31 * \operatorname{BETA}(1.77,1.71)$ & \\
\hline Service time of card room & Lognormal & $2+\operatorname{LOGN}(2.23,1.38)$ & Almaze \\
\hline $\begin{array}{l}\text { Service time of casher } \\
\text { room }\end{array}$ & Lognormal & $2+\operatorname{LOGN}(2.03,1.11)$ & Tsehaye \\
\hline $\begin{array}{l}\text { Transfer time from casher } \\
\text { to OPD }\end{array}$ & Beta & $1.24+3.55 *$ BETA $(1.03,0.761)$ & \\
\hline Service time of OPD1 & Beta & $8.11+4.62 *$ BETA $(1.22,1.6)$ & Nurse 1 \\
\hline Service time of OPD2 & Beta & $8.11+4.62 *$ BETA $(1.22,1.6)$ & Nurse 2 \\
\hline Service time of OPD3 & Beta & $8.11+4.62 *$ BETA $(1.22,1.6)$ & Nurse 3 \\
\hline $\begin{array}{l}\text { Service time of OPD1 } \\
\text { result teller }\end{array}$ & Normal & NORM $(4.34,0.723)$ & Nurse 1 \\
\hline $\begin{array}{l}\text { Service time of OPD2 } \\
\text { result teller }\end{array}$ & Normal & $\operatorname{NORM}(4.34,0.723)$ & Nurse 2 \\
\hline $\begin{array}{l}\text { Service time of OPD3 } \\
\text { result teller }\end{array}$ & Normal & NORM $(4.34,0.723)$ & Nurse 3 \\
\hline $\begin{array}{l}\text { Service time of pregenancy } \\
\text { test }\end{array}$ & Beta & $18.3+1.84 *$ BETA $(0.948,0.584)$ & Alemu \\
\hline
\end{tabular}




\begin{tabular}{|l|l|l|l|}
\hline $\begin{array}{l}\text { Service time of direct stool } \\
\text { examination test }\end{array}$ & Triangualr & TRIA $(47,50.1,52.5)$ & Adisuzemen \\
\hline TB test & Triangular & TRIA $(51,59.1,60)$ & \\
\hline Service time of urine test & Beta & $27+3.66 *$ BETA $(1.84,0.783)$ & Agerie \\
\hline $\begin{array}{l}\text { Service time of blood film } \\
\text { test }\end{array}$ & Normal & NORM $(58.1,2.64)$ & Agerie \\
\hline $\begin{array}{l}\text { Transfer time of OPD to } \\
\text { pharmacy }\end{array}$ & Normal & NORM $(3.73,0.873)$ & \\
\hline Service time of pharmacy & Beta & $1.29+2.48 *$ BETA $(3.44,2.3)$ & Pharmacist 1 \\
\hline
\end{tabular}

The above table shows that, the type of operation, statistical distribution of the operation time and the resource which is assigned in each operation.

\subsubsection{Development of standard simulation model}

The objective of model development is to determine which station of the system should be included in the model and how the model should flow to imitate the real system. The model development had hadbeen started with the declaration of the entity, the location of the service stations, generating path network and resources, declaration of the arrival and process programming.

The basic building blocks for arena models are modules. These flow chart and data objects define the process to simulate and chosen from panels in the Project Bar. Modules can divide into two main groups; Flowchart and Data. Flowchart modules describe the dynamic processes in the model. Flowchart modules defined as nodes or places through which entities flow, or where entities originate or leave the model. In arena, there are several templates (Panels) for developing the models. In the Basic Process panel, the kinds of flowchart modules available are Create, Dispose, Process, and Decide. Each type of flowchart module in the Basic Process panel has a distinctive shape. However, in other panels (such as the Advanced Process panel), there are many more flowchart-module types than there are reasonable shapes, so they are all represented by simple rectangles. Some panels (like Advanced Transfer) use colors in the rectangles to distinguish different types of flowchart modules. Data modules define the characteristics of various process elements, like entities, resources, and queues. They can also set up variables and other types of numerical values and expressions that relate to the whole model. Icons for data modules in the Project Bar look like little spreadsheets. The Basic Process panel's data modules are Entity, Queue, Resource, Variable, Schedule, and Set (other panels contain additional kinds of data modules). Entities do not flow through data modules, and data modules are not dragged into the model window; rather, data modules exist "behind the scenes" in a model to define different kinds of values, expressions, and conditions. This project is developing computer simulation model for the purpose of experimentation of the existing system and the improved one. Because of this, the model logic for the clinic is developed using Arena simulation software and shown below 


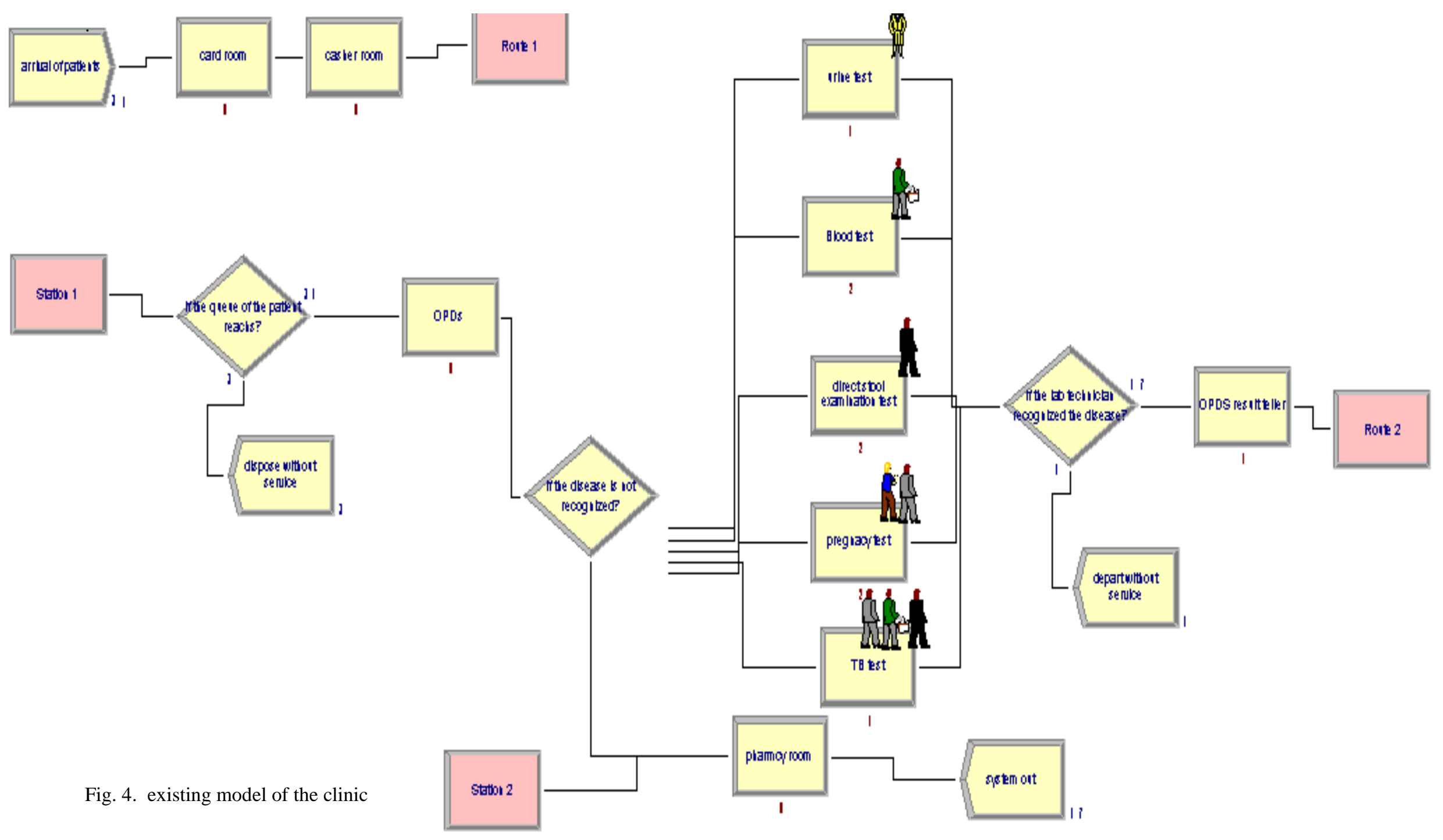




\section{Result and discussion}

\subsection{Model verification and validation}

Verification: One way for verification is by reviewing the SIMAN code and check if he model is doing exactly what have been planned for it to do. However, this way of verification needs a skill in the SIMAN programming language.

If there is no difference in statistical significance between the datasets, the model is considered valid. If not, the model needs additional work before analyzing the model reports (Aregawi, serajul, \& Iván, 2017).

A model, which includes all of the service specified under the system definition phase and capable of running without any errors or warnings, considered to be verifying successfully.

Validation: Modal validation made using statistical validity by comparing the output of the real system and the simulation model output of the existing system. If there is no statistically significant difference between the data sets, then the model considered as valid. Conversely, if there is a statistically significant difference, then the model is not valid and needs additional work before further analysis may conduct. The output of Bahir Dar clinic model in the real service system in eight hours is $50 \%$ of patients averagely. The output level the simulation run model in eight-hour is $52 \%$ of patients averagely. The output of the simulation model approaches the average output of the real system. Therefore, the model said to be represent the real system and to be valid.

\subsubsection{Number of replications}

(Aregawi, Serajul, \& Evan, 2017) and (aregawi, gebremedhin, teklewold, \& misgna, 2020) showed that Number of replication is number of simulation runs that should have executed to analyze statistically the differences between the simulation models. It has an integer value greater or equal to one.

The input distributions of simulation models are usually probabilistic in nature. This input variability naturally results in some variation in the output measures of performance. Because the output measures have some variation, it is inappropriate for the simulation practitioner to recommend any given course of action based on the results from a single simulation run or replication. To reduce the chance of making a wrong recommendation, it is necessary to run a number of simulation replications and then make the recommendations based on all of the available data. A common number of initial replication is ten. This provides a sufficient number of replications to have reasonable statistical confidence given that additional replications could always been subsequently added. In order to calculate number of replication, first calculate the mean and standard deviation of the first ten replications. The following table shows the average output and standard deviation for ten replications of Bahir Dar clinic. These summary statistical values have used to calculate the standard error of the data using the following formula.

Table 2. the first ten replications for Bahir Dar clinic

\begin{tabular}{|l|l|}
\hline Number of replications & Bahir Dar clinic output \\
\hline 1 & 38 \\
\hline 2 & 37 \\
\hline 3 & 33 \\
\hline 4 & 33 \\
\hline 5 & 34 \\
\hline 6 & 34 \\
\hline
\end{tabular}




\begin{tabular}{|l|l|}
\hline 7 & 34 \\
\hline 8 & 34 \\
\hline 9 & 34 \\
\hline 10 & 33 \\
\hline Mean $(\mathrm{X})$ & 34.4 \\
\hline Standard deviation $(\mathrm{S})$ & 1.224745 \\
\hline
\end{tabular}

The half width statistic used to help in determining the reliability of the results from the replication. In other word, half width is a sampling error in taking sample. Therefore, the value of half width can be simply determined by using:

Mean = summation of Bahir Dar clinic output/number of replication

$\mathrm{X}=(38+37+33+33+34+34+34+34+34+33) / 10$

$\mathrm{X}=344 / 10$

$\mathrm{X}=34.4$

Standard deviation(S):

$\mathrm{S}=\frac{\sqrt{[(\mathrm{xi}-\mathrm{X}) 2+\cdots+(\mathrm{x} 10-\mathrm{X}) 2]}}{n-1}$

where; $\mathrm{n}=$ number of replications

$\mathrm{S}=1.224745$

Half width $h o=t n-1 *\left(1-\frac{a}{2}\right) *\left(\frac{s}{\sqrt{n}}\right)$

where $\alpha$ is 0.05 from the confidence interval $95 \%$. $\mathrm{h}_{0}=\mathrm{t} 90.975 * \mathrm{~s} / V_{\mathrm{n}}$ from the $\mathrm{t}$ table $\mathrm{t} 90.975$ is 2.2622 . Half width for Bahir Dar clinic:

$\mathrm{h}_{0}=2.2622 * 1.224745 / \sqrt{10}$

$\mathrm{h}_{0}=0.876$

Actual number of replication

$n=Z^{2} * 1-\frac{a}{2} * \frac{S 2}{h 2 \quad 2}$

where $h 2=\frac{h o}{4}$

$n=\frac{n o h o^{2}}{h 2^{2}}$

Actual replication of the clinic:

$\mathrm{n}=\mathrm{Z}^{2} 0.975 * \mathrm{~S}^{2} / \mathrm{h}_{2}^{2}$, but $\mathrm{h}_{2}=0.876 / 4=0.219$

The waiting time is greater than the value added time, it shows that additional resources should be required to minimize the waiting time of the entity. $\mathrm{n}=(1.96)^{2 *}(1.224745)^{2} /(0.219)^{2}$

$\mathrm{n}=120$ option 1

$\mathrm{n} \cong \mathrm{n}_{0} * \mathrm{~h}_{0}^{2} / \mathrm{h}_{2}^{2}$

$\mathrm{n} \cong 10 *\left[(0.876)^{2} /(0.219)^{2}\right]$

$\mathrm{n} \cong 160 \ldots$ option 2

Therefore, from the two alternatives the maximum number of replication has selected that is 160 (Aregawi, Serajul, \& Evan, 2017).

\subsubsection{Simulation Model Run Results and Interpretation}

The output generated from run simulation model used to know or predict the performance of the system. The output analysis also used to predict the initial model performance and look after the weakness. Therefore, based on the output of the simulation model the performance measures analyzed for the existing service system of the clinic. The performance measures selected to analysis are entity performance, process performance, queue performance and resource performance.

Entity performance: the following points identified from the entity performance:

$\checkmark \quad$ The WIP of the service is high.

$\checkmark$ Half of the patients do not have the service within a day, because there is large queue and not enough servers to serve the patients.

$\checkmark$ The time required for patients to wait is higher due to the large number of queues there.

Queue performance: from the model run result of queue performance, the waiting time and number waiting in laboratory and card is higher. Conversely, 
the waiting time and number waiting of pharmacy, OPD and casher is low. This result shows that, there is unbalance allocation of resources to each station.

Process performance: from the model run results of process performance, the following points identified: The average waiting time of laboratory is higher their value added time. It also has higher waiting time of any other process of the system. This means that entities at this station spend more waiting time have been processed. Average waiting time for process like pharmacy, casher and OPD is low. Therefore, some resources from this station can share. Almost all of the patients that come to those stations always processed fully.

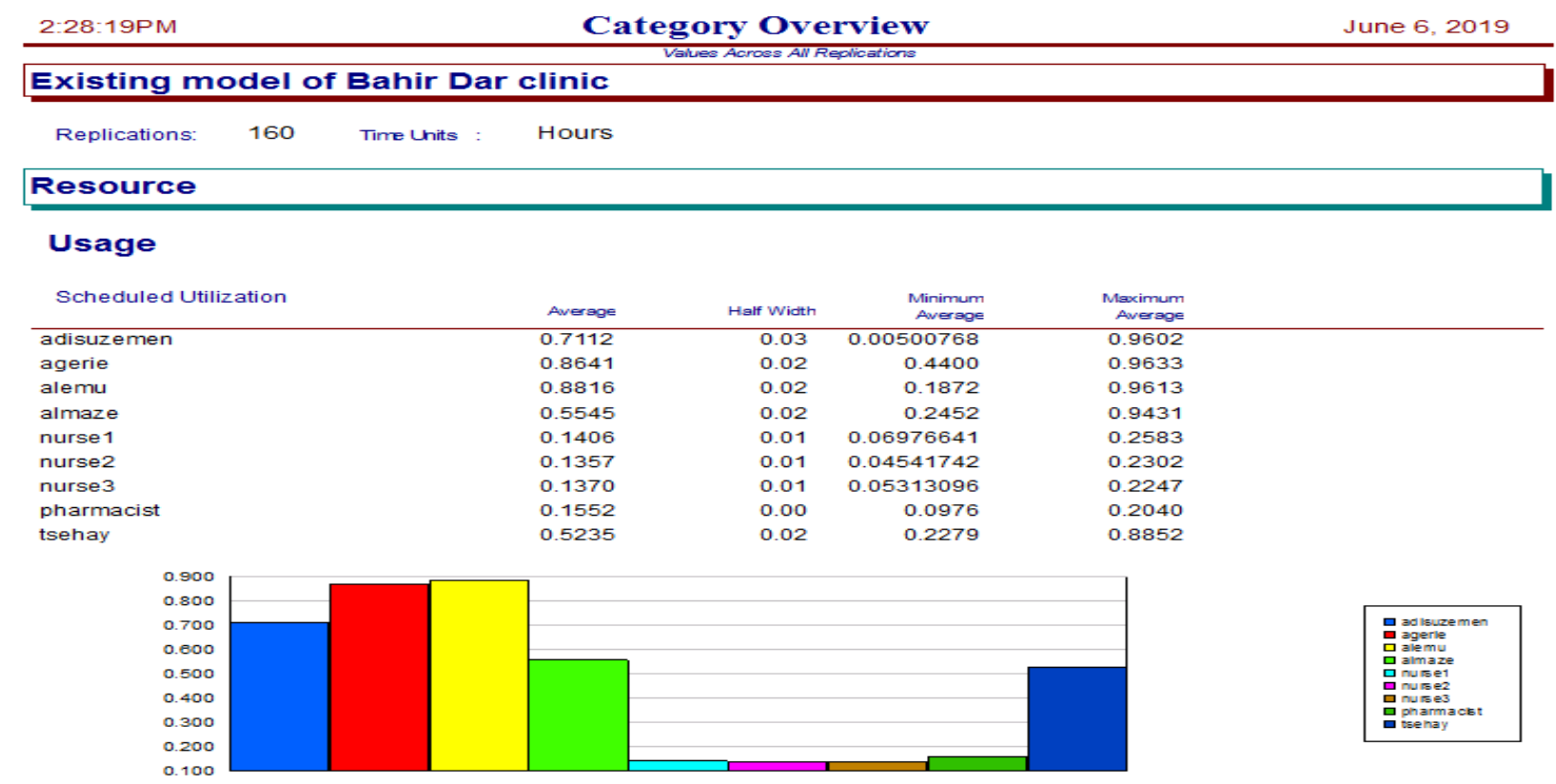

Fig. 5. utilization of resource in the system

Table 3. performance measures by running the existing model of the clinic

\begin{tabular}{|l|l|l|}
\hline $\begin{array}{l}\text { Serial } \\
\text { number }\end{array}$ & Performance indicators & Model result of the clinic \\
\hline 1 & Input & 67 \\
\hline 2 & Output(p) per eight hour & 34 \\
\hline 3 & Servicing rate(Rs) $=$ output/time $=34 / 480$ & 0.070833 patient per minute \\
\hline 4 & Work in progress $($ WIP $)$ & 19 \\
\hline 5 & Service efficiency $(\grave{\eta})=$ output/input $=(34 / 67) * 100$ & $50.746 \%$ \\
\hline
\end{tabular}




\subsection{Alternative simulation model development}

This chapter concerned on the development of different alternative models in which all problems that have been identified in the simulation model analysis and proposed for better performance of the system. DES can also allow decision makers to perform "what if" analyzes by changing scenarios and operating rules, to predict the possible impacts of a variety of policy alternatives before actually translating them into practice without any changes in current systems (Xiange, 2018).

Problems that are identified in the existing station simulation model are: Relatively high level of WIP is observed in some stations (operation), low efficiency

\subsubsection{Increase level of resource at bottleneck stations with high WIP}

These is focused on the change of the levels of resources at the bottleneck operations and high levels of work in process of the laboratory stations. Adding the resource at the bottleneck operation to reduces the work in progress and then increases the output of the system. Adding one resources for urine test that is more waiting time than other laboratory tests as shown with respect to the installed capacity and low service rate. For these problems, the following alternative models have proposed. These alternative models are:

1. Merging similar operations with low resource utilization together and assign one worker.

2. Increase level of resource at stations with high WIP.

3. Combining all alternative scenarios.

\subsubsection{Merging similar operations with low resource utilization together}

Stations with similar operations have low capacity utilization. However, these operations can be merging and assigned to one or two workers then select the best performance. Similar operations that can be merged together are listed in the following table.

\subsubsection{Combination of alternative scenarios}

These alternative scenarios are proposed by combining scenario two and scenario three together. The simulation run result of combination of alternative scenarios is shown below in the figure.

\subsubsection{Comparison of scenarios}

The above scenarios simulation run results are compared with the existing simulation model run results. The comparisons of each alternative for the system are as follows

Table 4. comparison scenarios of simulation model of Bahir Dar clinic

\begin{tabular}{|l|l|l|l|l|l|}
\hline Scenarios & Input & Output & WIP & $\begin{array}{l}\text { Service } \\
\text { rate(patients per } \\
\text { minute) }\end{array}$ & $\begin{array}{l}\text { Service } \\
\text { efficiency(\%) }\end{array}$ \\
\hline Existing system & 67 & 34 & 19 & 0.07083 & 50.75 \\
\hline Scenario 1 & 65 & 34 & 17 & 0.07083 & 52.3 \\
\hline Scenario 2 & 66 & 40 & 16 & 0.0833 & 60.61 \\
\hline Scenario 3 & 66 & 40 & 16 & 0.0833 & 60.61 \\
\hline
\end{tabular}




\begin{tabular}{|l|l|l|l|l|l|}
\hline Combined scenario 2 and 3 & 66 & 40 & 16 & 0.0833 & 60.61 \\
\hline Combined scenario 1 and 3 & 66 & 40 & 16 & 0.0833 & 60.61 \\
\hline
\end{tabular}

\begin{tabular}{|c|c|c|c|c|c|c|}
\hline & \multicolumn{3}{|c|}{ Scenario Properties } & \multicolumn{3}{|c|}{ Responses } \\
\hline Sali & s. Name & Program File & Reps & $\begin{array}{c}\text { System.Num } \\
\text { berOut }\end{array}$ & \begin{tabular}{|c|} 
patient.Numb \\
erln
\end{tabular} & patient:WIP \\
\hline 1 & Scenario 1 & $6:$ adding one resource in to the urine test.p & 160 & 40.094 & 66.206 & 16.174 \\
\hline 2 & (1) Scenario 2 & 1: merging similar operation with low resource utilization together and assign two nurses.p & 160 & 33.994 & 67.581 & 19.530 \\
\hline 3 & 4 Scenario 3 & 2: merging similar operation with low resource utilization together and assign two nurses.Backup.p & 1 & 38.000 & 89.000 & 27.541 \\
\hline 4 & (1) Scenario 4 & 9: combine scenario 1 and scenario 3.p & 160 & 40.094 & 66.206 & 16.174 \\
\hline 5 & (1) Scenario 5 & 1: combined scenario 2 and scenario 3. Backup.p & 160 & 39.844 & 66.856 & 16.816 \\
\hline
\end{tabular}

Fig. 6. Scenario analysis

The performance measure of the proposed scenario is better than the existing performance measure for the model of the system. From the above proposed scenarios scenario 3 , combined scenario 1 and 3 and combined scenario 2 and 3 gives equal performance measure for the model of the system. However, combined scenario 2 and 3 gives better performance measure for the model of the system because this result gives by using low resources than the other scenarios that have the same performance measurements Therefore, the company recommended that to take considerations about combined scenario 2 and 3 .

\section{Conclusion}

In this paper the service performance analysis and improvement has been analyzing using discrete event simulation. The simulation model of the system has been done by arena master development 14-version software. The performance measurement for this system are output, service rate, service efficiency and it is directly related to waiting time, work in progress, resource utilization.

Simulation model was building for Bahir Dar clinic and then prepared the proposed model for the system. Based on the simulation run result; the output of the existing system is low due to presence of bottlenecks on the service system. Moreover, the station with the largest queue and high resource utilization are identified as a bottleneck for the health care. The bottlenecks are identified and have reduced by using reassigning the existing resources and add new resources and merging the similar services, and nurses have low resource utilization relatively with the other resources of the health care. Accordingly, in the proposed model, which is the combination of scenario 2 and 3; the service efficiency of the system has increased by 9.86 percent, the work in progress (WIP) are reduced by 3 patients from the system and the service capacity of the system is increased 34 to 40 patients per day due to the reduction of bottleneck stations.

\section{Bibliography}

Appah, Sam, A., \& Alex. (2014). Queuing theory and the management of Waiting-time in Hospitals: The case of Anglo Gold Ashanti Hospital in Ghana. International Journal of Academic Research in Business and Social Sciences, 34-44.

aregawi, y., gebremedhin, g., teklewold, m., \& misgna, h. (2020). Productivity Improvement through Line Balancing by Using Simulation Modeling (Case study Almeda Garment Factory) . Journal of Optimization in Industrial Engineering, 153-165.

Aregawi, Y., Serajul, H., \& Evan, s. M. (2017). Optimal layout Design by line balancing using simulation modeling. proceeding of the international conference on 
Industrial engineering and operation management Bogota, (pp. 228-244). Bogota.

Aregawi, y., serajul, h., \& Iván, S. M. (2017). Identification Using Time Study and Simulation Modeling of Apparel Industries. International Conference on Industrial Engineering and Operations Management., (pp. 321331). Bogota.

Eduardo, C., Manel, T., MaLuisa, I., Francisco, E., \& Emilio, L. (2012). Simulation Optimization for Healthcare Emergency Departments. International Conference on Computational Science (pp. 1464 -1473). Procedia Computer Science.

Eshetie, b., Selam, Y., \& Sisay, G. (2018). Service Performance Improvement Model: The Case of Teklehaymanot General Hospital. Journal of Optimization in Industrial Engineering, 23-33.

Globerman, S. (2013). Reducing Wait Times for Health Care: What Canada Can Learn from Theory and International Experience. Fraser Institute.

Haussmann. (1970). waiting time as an index of quality of nursing care.

Heflin, \& Harrell. (1998). Healthcare simulation modeling and optimization using MedModel.

Israel, G. D. (1992). Determining sample size. University of Flordia.

Junqiao, C., David, C., Mónica, D. O., \& Alexandra, F. (2019). An Analysis on the Research Orientations in Healthcare Simulation Modeling. Proceedings of the Modeling and Simulation in Medicine Symposium. doi:DOI: $10.22360 /$ springsi

Kelton, W. D. (2002). simulation with arena second edition. Mc Graw Hill.

MIELCZAREK, B. (2016). REVIEW OF MODELLING APPROACHES FOR HEALTHCARE SIMULATION O P ERA TI O NSR ESEARCHA NDDECIS $I O N S$, (pp. 55-72). doi:DOI: 10.5277/ord160104, 5572

Sally, B., \& Shivam, D. J. (2010). Combining system dynamics and discrete event simulation health care. Winter Simulation Conference (pp. 2293-2301). IEEE.
Samuel Fomundam, J. H. (2007). A Survey of Queuing Theory Applications in Healthcare. ISR .

Sheldon, H., Shane, N. H., \& James, R. S. (2006). in Operations Research \& Management. International Series in Operations Research \& Management Science book series.

Sulaf, A. (2015). Simulation modelling in healthcare: Challenges and trends. international Conference on Applied Human Factors and Ergonomics, (pp. 301-307).

Topaloglu, S. (2009). A shift scheduling model for employees with different seniority levels and an application in healthcare. European Journal of Operational Research , Seyda Topaloglu (2009). A shift scheduling model for employees with different seniority levels and an appli198(3), 943-957.

Umar, I., Oche, M. O., \& Umar, A. S. (2011). Patient waiting time in a tertiary health institution in Northern Nigeria. Journal of Public Health and Epidemiology, 78-82.

Vos, L., Groothus, S., \& Van, M. (2007). Evaluting hospital design from an operation management perspective. Springer Science + Business Media, LLC.

Xiange, Z. (2018). Application of discrete event simulation in health care: a systematic review. Health Services Research. 